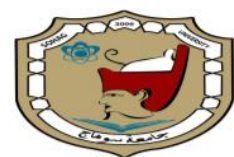

Sohag University

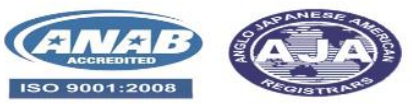

Sohag Medical Journal

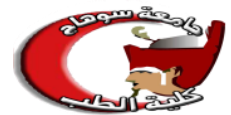

Faculty of Medicine

\title{
Various modalities for pain control after open cardiac surgeries
}

\author{
Wesam Abd El Galil Abu Elwafa, *Samar Thabet Abu Bakre, \\ *Khaled Abdelfattah Mohamed Abdelfattah* \\ * Department of anesthesia, intensive care and pain management, Faculty of \\ Medicine, Sohag University, Sohag, Egypt
}

\begin{abstract}
We addressed the different analgesic strategies for pain relief after open cardiac surgeries in this study. While opioid-based is traditionally the cornerstone of postoperative analgesia, there's growing evidence to support a multimodal approach to attenuate opioid side effects, minimize pain rating, and attenuate the length of hospital stay, and facilitate improved rehabilitation strategies that provide a crucial component of multimodal regimens. Patients had unusual special features in their pain perception which provide variable modes of pain treatment. For the treatment of pain after cardiac surgeries, several different agents (opioid vs. non-opioid), routes (oral, intravenous, neuraxial, regional), and modes (patient-controlled vs.as needed) are accessible.

Keywords: postoperative pain relief, heart surgery, opioids, NSAIDS, regional techniques.
\end{abstract}

\section{Introduction}

\section{Cardiac Surgery and Pain}

Pain definition. The Task Force on Taxonomy (1) of the International Association for the Study of Pain describes the pain as an uncom-fortable sensory and emotional disorder connected to or characterized by actual or potential tissue damage. (2).

During cardiac surgery, there are numerous sources of pain; sternotomy, sternal or rib retraction, pericard-iotomy, internal mammary artery, saphenous vein harvesting, pleura surgical manipulation, chest tube placement, and other musculoskeletal damage throughout the procedure. $(\mathbf{3 , 4})$.

There are both short term and potential consequences of post-sternotomy pain. The immediate postoperative phase can be complicated by bad acute postoperative pain and can cause chronic pain as well. (5). Pain treatment is aimed at alleviating or reducing pain. Usually, pain is or is not treated phar- macologically. (6). With the arrival of the new anesthesiology, Pain relief fro$\mathrm{m}$ the intraoperative into the perioperative phase has been altered. One of the main critical components of adequate postoperative patient treatment is postoperative pain control. $(\mathbf{7 , 8 )}$.

Several unfavorable issues, hemodynamic dysfunction (hypertension, tachycardia, and vasoconstriction), immunological disturbance, metabolic (extensive catabolism), and hemostatic disorder (platelet activation) could result from inadequate postoperative pain management. $(\mathbf{9 , 1 0})$

Unique postoperative pain control techniques following heart surgery. For the control of postoperative pain after heart surgery, there are many approaches available that can even be classified as strategies for pharmacological and nonpharmacological. Both of 
those approaches have benefits and drawbacks.

Those different pain relief techniques including:

-Intravenous administration of opioids, NSADs, alpha-adrenergic medication, and gabapentiniods

-Penetration of local anesthetics

- Blocked Nerve

- Approaches to Epidural

- Techniques Intrathecal

-Analgesic adjuvant. (11)

\section{Pharmacological pain management}

After surgery, successful pain management requires a multimodal approach and thus the use of assorted drugs with multiple modes of action. Pharmacological management methods are widely used for opioids, NSAIDs, and more recently anticonvulsants. (12)

Shortly after GIT procedures, opioids such as morphine and fentanyl are used to manage moderate to severe pain. Other drugs, such as ibuprofen, paracetamol, and oxycodone, are sometimes used along with opioids in the treatment of moderate to serious pain. (13)

While the cornerstone of postoperative analgesia is traditionally opioid-based, there's growing evidence to support a multimodal approach to scale back opioid side effects (such as nausea, and ileus), and improve pain scores. $(\mathbf{1 4 , 1 5})$

\section{Non-pharmacological pain manage- ment.}

Clinical advice advises the use of nonpharmacological pain management approaches in an adult intensive care unit. This can alleviate pain, but if used along with pharmacological procedures, it is best. (16).

This requires exercise, psychological planning, cognitive behavioral therapy, heat, and cold therapy, physical treatment, trigeminal stimulation or massage, music therapy, and emotional support. $(17,18)$.
Acupuncture and hypnosis have also been found to be beneficial for postoperative pain relief. It has been shown that parasternal block and transcutaneous electrical nerve stimulation provide powerful analgesia and attenuate the need to use opioids for postoperative cardiac surgery in patients. (19).

\section{Analgesia using opioids}

Morphine and its derivatives have emerged as the most effective analgesics for postoperative pain relief. (20). The Analgesic Ladder has been developed to treat acute pain by the World Federation of Societies of Anesthesiologists (WFSA). (21).

It is best to use analgesics or substances with less pronounced dependency or addiction. (22)

Opioids bind to receptors and modulate the function of nociceptors in the central nervous system and peripheral tissues. The most commonly used intravenous opiates for postoperative pain are morphine, hydromorphone, and fentanyl. $(\mathbf{2 3}, \mathbf{2 4})$

For opiates, morphine is generally used as a normal substitute. It had a delayed onset of action occurring in 1 to 2 hours with a peak effect. $(\mathbf{2 3}, \mathbf{2 4})$

Fentanyl and hydromorphone are derivatives of synthetic opioids that are more active, have a shorter action initiation, and have shorter half-lives than crude opioids(morphine). Both opioids have significant side effects that limit their use. Respiratory depression, which can lead to hypoxia and respiratory arrest, is the most important side effect. In addition, these medications have also a common side effect of nausea, vomiting, pruritus, and decreased bowel motility that contributes to ileus and constipation. $(\mathbf{2 3}, \mathbf{2 4})$.

Long term use of opioids induces dependency and addiction. Oral opioids are mostly initiated after the patient can manage oral consumption and are continued after hospital discharge. $(\mathbf{2 5 , 2 6 )}$ 


\section{Multimodal analgesia}

Multimodal analgesia is now the concept for acute postoperative pain relief, a phrase first proposed by Kehlet, and Dahl (27).

Multimodal strategies include the use of two or more analgesic drugs acting in synergy with distinct modes of action. These medications may also be given preoperatively, intraoperatively, and /or postoperatively by either similar or different routes of administration. (28). The use of multiple agents with different mechanisms of action allows for lower doses of individual agents by targeting different pain receptors within the central and peripheral nervous systems resulting in a lower risk of adverse effects. A shorter hospitallization period, better patient recovery, rehabilitation, and reduced care costs may further result in a lower incidence of adverse effects and better pain control. $(29,30)$

\section{Tramadol.}

Tramadol may be a weak opioid agonist and has two mechanisms of action: binding to the $\mu$-opioid receptor and inhibiting the reuptake of serotonin and norepinephrine. Theoretically, its weak opioid effect makes it beneficial (less respiratory depression, pruritus); however, tramadol may be a substrate for the cytochrome P450 CYP2D6 liver enzyme, so any agents that can inhibit or trigger that enzyme is capable to interfere with tramadol. (31)

\section{Magnesium}

Like the antagonist effect of the calcium channel, magnesium sulfate has been suggested to possess analgesic properties and to dam the NMDA channel, which mediates opioid tolerance, hyperalgesia, and chronic states of pain. However, it is unclear whether the analgesic effect of magnesium sulfate is mediated by central or peripheral mechanisms because cerebrospinal conce- ntrations that are high enough to modulate analgesia by NMDA inhibition are difficult to be reached. $(\mathbf{3 2 , 3 3 )}$

\section{The Gabapentinoids}

Gabapentin and pregabalin are experimental antiepileptic drugs that also have a positive influence on neuropathic pain. $(\mathbf{3 4 , 3 5 )}$ and postoperative pain respectively. By binding with the alpha 2 delta subunit of voltage-sensitive calcium channel, they exert an antinociceptive effect. As well as having a central antiallodynic effect, they also inhibit pain transmission. $(36,37)$

The drug is only available as an oral formulation, and also differs in bioavailability. Gabapentin is absorbed in the intestine by a saturated aminoalkanoic acid transport mechanism, so that bioavailability varies inversely with dose. (38).

From extreme side effects and medication reactions, all are saved within the clinically effective dosage. Gabapentin also can be beneficial in preventing postoperative chronic pain $(\mathbf{3 7 , 3 9})$

\section{Corticosteroids:}

Glucocorticoids are COX 2 inhibitors and have many effects on the synthesis of prostaglandins, explaining their mild analgesic efficacy. The start of its action is several hours after administration, so preoperative administration is needed. The dosage of dexamethasone ranges from 4-16 mg IV. (40).

Besides its antiemetic effect, dexamethasone is used routinely to have a mild analgesic effect. The protection of the upper doses is questionable and no preventable effect on chronic postoperative pain has been shown with dexamethasone. (40)

Other corticosteroids appear to have less of an effect. Methylprednisolone induces mild analgesia at the 30-125 $\mathrm{mg}$ IV level. Fifty $\mathrm{mg}$ of prednisone orally had little effect on postoperative pain. (40). 
Adrenoceptor's Alpha-2 agonists The role of Alpha-2 agonist in pain pathways

Alpha-2 Adrenergic receptors are found in both presynaptic and postsyn-aptic neurons in both the central and peripheral nervous systems. The activeetion of presynaptic receptors contributes to the propagation of the feedback loop that prevents the release of norepinephrine. Activation of postsynaptic receptors inside the central nervous system decrease sympathetic activity. The locus coeruleus within the brainstem has high concentrations of alpha-2 adrenoceptors at the supraspinal level. It is the cornerstone of the medullo-spinal noradrenergic pathway, recognized as an essential nociceptive neurotransmission modulator. Stimulation of alpha-2 receptors within the subs-tantia-gelatinosa within the dorsal horn at the spinal level contributes to the inhibition of nociceptive neurons and substance-P production. Examples of drugs acting on such receptors include clonidine and dexmedetomidine. (41)

\section{Dexmedetomidine Medication}

Dexmedetomidine can be highly selective in nature as a relatively recent central alpha- 2 agonist. The sedative, pro-anesthetic, and pro-analgesic activeity at $0.5-2$ micrograms $/ \mathrm{kg}$ was administered intravenously as a result of the ability to suppress the central sympathetic response through mechanisms that are still unresolved. $(\mathbf{4 2 , 4 3 )}$ It also minimizes opioid-induced muscle rigidity, decreases postoperative shivering, causes decreased respiratory discomfort, and it has a hemodynamic stabilizing impact. (52,53)

\section{Neuraxial Analgesia (Epidural and Spinal)}

The use of epidural analgesia in cardiac surgery has been investigated in various trials, clinical studies, and met- a-analyses. The potential benefits and associated risks of thoracic epidural analgesia remain controv-ersial. (44)

Attenuated stress response, thoracic cardiac sympathectomy, enhanced coronary blood flow with increased myocardial oxygen supply, decreased myocardial ischemia, decreased arrhy-thmia, decreased intubation period, and fewer complications are the potential advantages of epidural analgesia in cardiac surgery. (44)

Just 7 percent of anesthesiologists used epidural procedures in adult cardiac surgery according to a study in 2001; however, its use had increased since that time. (45)

The apprehension of heparin anticoagulation-related epidural hematoma has limited the widespread use of epid-ural analgesia in cardiac surgery. (45)

\section{Peripheral nerve blocks}

In complementing other analgesic techniques, nerve blocks such as intercostal, intrapleural, and paravertebral blocks are successful techniques. (46)

\section{Intercostal Block}

These blocks are also used for analgesia during cardiothoracic surgery. Intercostal nerve blocks have also greatly decreased additional analgesic needs. (47)

Both intraoperatively and postoperatively, intercostal nerve blocks can be used. Local anesthetics following cardiothoracic surgery can provide analgesia and enhance respiratory function. (48)

\section{Intrapleural Block}

Local anesthetic drug delivery via bolus or continuous infusion may be given by an intrapleural catheter posit-ioned between the visceral and pleura. In this method, toxicity due to the systemic absorption of local anesthetic drugs is frequent. (48)

\section{Paravertebral Analgesia}


The thoracic paravertebral block can be a local anesthetic solution adjacent to the thoracic vertebrae, near the spot where spinal nerves originate from the foramina intervertebral (49).

This blockade is sometimes provided as a single or multisite injection, as a unilateral or bilateral injection, and as a catheter-based endless infusion. This was used in thoracotomy, and post sternotomy heart surgery. (50).

\section{lidocaine}

Lidocaine is the local anesthetic that is most commonly used in penetration and for central neuraxial and peripheral nerve blocks. This was used to treat arrhythmias, chronic neuropathic pain, and Bier's block intravenously. Lidocaine is at least as effective for the treatment of chronic neuropathic pain as other anti-neuropathic pain medications, according to the Cochrane review. and is resistant to serious side effects. Lidocaine contains anti-inflammatory, analgesic, and anti-hyperalgesic agents. (51).

Blocking receptors such as Na-channels, NMDA, and G-protein are thought to mediate the analgesic effects. (52)

\section{Wound Infiltration}

An attractive technique for treating pain after cardiac surgery with sternotomy through continuous penetration of the local wound. Local anesthetics are exempt from opioid-related adverse effects that cause respiratory depression, drowsiness, sedation, and nausea and vomiting. Local anesthetics, on the other hand, are sometimes delivered with specifically manufactured catheters at the site of surgical trauma (e.g., sternotomy wound in cardiac surgery), and it is possible to avoid the complication linked to central neuraxial procedures, epidural/spinal hematoma, and systemic hypotension. In cardiac surgery, there are currently few studies using local infusion analgesia and the results are therefore somewhat conflictting. (53,54.55)

\section{Conclusion}

For the treatment of postoperative pain following cardiac surgery, several methods are available, including intravenous administration of analgesic drugs such as opioids and non-opioids, local anesthetics infiltration, nerve blocks, and neuraxial methods. Traditionally, after surgery, analgesia is given by opioid analgesic administration. However, extreme opioids administration is associated with several side effects including respiratory depression, sedation and lethargy, vomiting, and nausea, constipation, retentiveness, purities, and ileus.

For superior pain control, doctors, therefore, use multimodal regimens such as non-opioid analgesic medication for pain relief.

\section{Reference:}

1-International Association for Study of Pain. International Association for the Study of Pain, Classification of Chronic Pain .2011; Second Edition (Revised). Accessed 25 May 2017. Retrieved from https://www.iasppain.org/Publications News/Content.aspx?ItemNumber $=1673$

2-Merskey H, Bogduk N. Classification of Chronic Pain Descriptions of Chronic Pain Syndromes and Definitions of Pain Terms. Task Force on Taxonomy of the International Association for the Study of Pain.1994; 2nd ed. Seattle, WA: IASP Press.

3-Fayaz, M. K., R. J. Abel, S. C. Pugh, J. E. Hall, G. Djaiani, and J. S. Mecklenburgh. "Opioid-sparing effects of diclofenac and paracetamol lead to improved outcomes after cardiac surgery." J Cardiothorac Vasc Anesth .2004;18(6): 742-747.

4-Chandrakanta, A, and P. S. Glass (2011). "Multimodal therapies for postoperative nausea and vomiting, and pain." $\underline{\mathrm{Br} \mathrm{J}}$ Anaesth 107 Suppl 1: i27-40. 
5-Macintyre, P. E, and S. M. Walker. "The scientific evidence for acute pain treatment." Curr Opin Anaesthesiol.2010; 23(5): 623-628.

6-MedicineNet.com. Medical Definition of Pain management. Accessed. 2016; $\underline{\text { Retrieved }}$ from http://www.medicinenet.com/script/mai n/art.asp?articlek $\mathrm{y}=10513$

7-Liu, S. S, and C. L. Wu. "Effect of postoperative analgesia on major postoperative complications: a systematic update of the evidence." Anesth Analg.2007; 104(3): 689-702.

8-Imani, F. "Postoperative pain management." Anesth Pain Med.2011; 1(1): 6-7.

9-Kehlet, H, and K. Holte. "Effect of postoperative analgesia on surgical outcome." $\mathrm{Br} \mathrm{J}$ Anaesth.2001; 87(1): 62-72.

10-Olivier JF. Neuraxial analgesia in cardiac surgery: a review of risks. Tech Reg Anesth Pain Manag.2008; 12:26-31

11-Karagoz, H. Y., B. Sonmez, B. Bakkaloglu, M. Kurtoglu, M. Erdinc, A. Turkeli, and K. Bayazit. "Coronary artery bypass grafting in the conscious patient without endotracheal general anesthesia." Ann Thorac Surg.2000; 70(1): 91-96.

12-Cogan, J. Pain management after cardiac surgery. Semin Cardiothorac Vasc Anesth.2010; 14(3): 201-204.

13-Garimella, V, and C. Cellini. "Postoperative pain control." Clin Colon Rectal Surg.2013; 26(3): 191196.

14-Kalkman, C. J., K. Visser, J. Moen, G. J. Bonsel, D. E. Grobbee, and K. G. Moons. "Preoperative prediction of severe postoperative pain." Pain.2003; 105(3): 415-423.

15-Abrishami, A., J. Chan, F. Chung, and J. Wong. "Preoperative pain sensitivity and its correlation with postoperative pain and analgesic consumption: a qualitative systematic review." Anesthesiology.2011; 114(2): 445-457.
16-Martorella, G., M. Boitor, C. Michaud, and C. Gelinas. "Feasibility and acceptability of hand massage therapy for pain management of postoperative cardiac surgery patients in the intensive care unit." Heart Lung.2014; 43(5): 437444.

17-Gelinas, C., C. Arbour, C. Michaud, L. Robar, and J. Cote. "Patients and ICU nurses' perspectives on nonpharmacological interventions for pain management." Nurs Crit Care. 2013; 18(6): 307-318.

18-Kipu (online). Käypä hoito -suositus. Suomalaisen Lääkäriseuran Duodecimin,Suomen Anestesiologiyhdistyksen ja Suomen Yleislääketieteen yhdistyksenasettama työryhmä. Helsinki: Suomalainen Lääkäriseura Duodecim .2015. Referred to 13.06.2017.. Available online: www.kaypahoito.fi

19-Ozturk, N. K., E. D. Baki, A. S. Kavakli, A. S. Sahin, R. U. Ayoglu, A. Karaveli, M. Emmiler, K. Inanoglu, and B. Karsli. "Comparison of transcutaneus electrical nerve stimulation and parasternal block for postoperative pain management after cardiac surgery." Pain Res Manag.2015

20-Hamilton, G. R, and T. F. Baskett. "In the arms of Morpheus, the development of morphine for postoperative pain relief." Can J Anaesth.2000; 47(4): 367374.

21-World Health Organization. Essential medicines: WHO model list. 14th ed.2005. Available from: http://whqlibdoc.who.int/hq/2005/a870 17 eng.pdf.

22-Leegaard, M., and M. S. Fagermoen. "Patients' key experiences after coronary artery bypass grafting: a synthesis of qualitative studies." Scand J Caring Sci.2008; 22(4): 616-628.

23-Goettsch, W. G., M. P. Sukel, D. L. van der Peet, M. M. van Riemsdijk, and R. M. Herings. "In-hospital use of opioids increases the rate of coded postoperative paralytic ileus." Pharmacoepidemiol Drug Saf.2007; 16(6): 668-674. 
24-Barletta, J. F., T. Asgeirsson, and A. J. Senagore. Influence of intravenous opioid dose on postoperative ileus." Ann Pharmacother.2011; 45(7-8): 916923.

25-Levy, B. F., H. S. Tilney, H. M. Dowson, and T. A. Rockall. "A systematic review of postoperative analgesia following laparoscopic colorectal surgery." $\quad$ Colorectal Dis. 2010; 12(1): 5-15.

26-Zafar, N., R. Davies, G. L. Greenslade, and A. R. Dixon. "The evolution of analgesia in an 'accelerated' recovery program for resectional laparoscopic colorectal surgery with anastomosis." Colorectal Dis.2010; 12(2): 119-124.

27-Kehlet, H, and J. B. Dahl. "The value of "multimodal" or "balanced analgesia" in postoperative pain treatment." Anesth Analg.1993; 77(5): 1048-1056.

28-Manworren, R. C. "Multimodal pain management and the future of a personalized medicine approach to pain." AORN .2015; 101(3): 308-314; quiz 315-308.

29-Buvanendran, A., J. S. Kroin, C. J. Della Valle, M. Kari, M. Moric, and K. J. Tuman. "Perioperative oral pregabalin reduces chronic pain after total knee arthroplasty: a prospective, randomized, controlled trial." Anesth Analg.2010; 110(1): 199-207.

30-Vaughan-ShawPG, Fecher IC, Harriss, Knight JS. A meta-analysis of the effectiveness of the opioid receptor antagonist alvimopan in reducing hospital length of stay and time to GI recovery in patients enrolled in a standardized accelerated recovery program after abdominal surgery. Dis Colon Rectum.2012; 55:611-620.

31-Gibbison, B., C. R. Bailey, and A. A. Klein. "Tramadol - the Marmite drug." Anesthesia.2015; 70(2): 125-130.

32-Ryu, J. H., M. H. Kang, K. S. Park, and S. H. Do. "Effects of magnesium sulfate on intraoperative anesthetic requirements and postoperative analgesia in gynecology patients receiving total intravenous anesthesia." Br J Anaesth.2008; 100(3): 397-403.

33-Dabbagh, A., H. Elyasi, S. S. Razavi, M. Fathi, and S. Rajaei. "Intravenous magnesium sulfate for postoperative pain in patients undergoing lower limb orthopedic surgery." Acta Anaesthesiol Scand.2009; 53(8):1088-1091

34-Moore, R. A., S. Straube, P. J. Wiffen, S. Derry, and H. J. McQuay. "Pregabalin for acute and chronic pain in adults." Cochrane Database Syst Rev. 2009;(3): CD007076.

35-Moore, R. A., P. J. Wiffen, S. Derry, and H. J. McQuay. "Gabapentin for chronic neuropathic pain and fibromyalgia in adults." Cochrane Database Syst Rev. 2011; (3): CD007938.

36-Dauri, M., S. Faria, A. Gatti, L. Celidonio, R. Carpenedo, and A. F. Sabato. "Gabapentin and pregabalin for acute postoperative pain management. A systematic-narrative review of the recent clinical evidence." Curr Drug Targets.2009; 10(8): 716-733.

37-Schmidt, P. C., G. Ruchelli, S. C. Mackey, and I. R. Carroll. "Perioperative gabapentinoids: choice of agent, dose, timing, and effects on chronic postsurgical pain." Anesthesiology.2013; 119(5): 12151221.

38-Rose, M. A, and P. C. Kam. "Gabapentin: pharmacology and its use in pain management." Anesthesia.2002; 57(5): 451-462

39-Clarke H, Bonin RP, Orser BA, et al. The prevention of chronic postsurgical pain using gabapentin and pregabalin: a combined systematic review and metaanalysis. Anesth An-alg.2012; 115:42842

40-Hval, K., K. S. Thagaard, E. Schlichting, and J. Raeder. "The prolonged postoperative analgesic effect when dexamethasone is added to a nonsteroidal anti-inflammatory drug (rofecoxib) before breast surgery." Anesth Analg.2007;105(2): 481-486. 
41-Blaudszun, G., C. Lysakowski, N. Elia, and M. R. Tramer. "Effect of perioperative systemic alpha2 agonists on postoperative morphine consumption and pain intensity: systematic review and meta-analysis of randomized controlled trials." Anesthesiology.2012; 116(6): 1312-1322.

42-Gurbet, A., E. Basagan-Mogol, G. Turker, F. Ugun, F. N. Kaya, and B. Ozcan. "Intraoperative infusion of dexmedetomidine reduces perioperative analgesic requirements." Can J Anaesth.2006; 53(7): 646-652.

43-Dholakia, C., G. Beverstein, M. Garren, C. Nemergut, J. Boncyk, and J. C. Gould. "The impact of perioperative dexmedetomidine infusion on postoperative narcotic use and duration of stay after laparoscopic bariatric surgery." J Gastrointest Surg.2007; 11(11): 1556-1559.

44-Chaney, M. A. "Intrathecal, and epidural anesthesia, and analgesia for cardiac surgery." Anesth Analg.2006; 102(1): 45-64.

45-Goldstein, S., D. Dean, S. J. Kim, K. Cocozello, J. Grofsik, P. Silver, and R. P. Cody. "A survey of spinal and epidural techniques in adult cardiac surgery." J Cardiothoracic Vasc Anesth.2001;15(2): 158-168.

46-Rahimzadeh P, Faiz HS, Ziyaeifard M, Niknam K. Effectiveness of adding ketamine to ropivacaine infusion via femoral nerve catheter after knee anterior cruciate ligament repair. Journal of Research in Medical Sciences.2013;18:632-636

47-Joao, P. R, and F. Faria Junior. "[Immediate post-operative care following cardiac surgery]." J Pediatr (Rio J).2003; 79 Suppl 2: S213-222.
48-Kalso, E., S. Mennander, T. Tasmuth, and E. Nilsson. "Chronic poststernotomy pain." Acta Anaesthesiol Scand.2001; 45(8): 935-939.

49-Karmakar, M. K. "Thoracic paravertebral block." Anesthesiology.2001; 95(3): 771-780.

50-Carmona, P., J. Lagunes, S. Canovas, J. de Andres, and I. Marques. "The role of continuous thoracic paravertebral block for fast-track anesthesia after cardiac surgery via thoracotomy." J Cardiothorac Vasc Anesth.2011;25(1): 205-206.

51-Challapalli, V., I. W. Tremont-Lukats, E. D. McNicol, J. Lau, and D. B. Carr. "Systemic administration of local anesthetic agents to relieve neuropathic pain." Cochrane Database Syst Rev.2005;(4): CD003345.

52-McCarthy, G. C., S. A. Megalla, and A. S. Habib. "Impact of intravenous lidocaine infusion on postoperative analgesia and recovery from surgery: a systematic review of randomized controlled trials." Drugs.2010;70(9): 1149-.1163.

53-White, P. F., S. Rawal, P. Latham, S. Markowitz, T. Issioui, L. Chi, S. Dellaria, C. Shi, L. Morse, and C. Ing. "Use of a continuous local anesthetic infusion for pain management after median sternotomy." Anesthesiology.2003;99(4): 918-923.

54-Dowling, R., K. Thielmeier, A. Ghaly, D. Barber, T. Boice, and A. Dine. Improved pain control after cardiac surgery: results of a randomized, double-blind, clinical trial. J Thorac Cardiovasc Surg.2003; 126(5): 12711278. 